\title{
Scintigraphic parathyroid imaging: concepts and new developments
}

This article was published in the following Dove Press journal:

Research and Reports in Nuclear Medicine

22 June 2015

Number of times this article has been viewed

\author{
Saud A Alenezi ${ }^{1,2}$ \\ Saqr M Asa'ad ${ }^{2}$ \\ Abdelhamid H Elgazzar' \\ 'Department of Nuclear Medicine, \\ Faculty of Medicine, Kuwait University, \\ Kuwait; ${ }^{2}$ Sheikh Jaber Al-Ahmad \\ Nuclear Medicine and Molecular \\ Imaging Center, Kuwait
}

\begin{abstract}
Hyperparathyroidism is a condition caused by increased secretion of the parathyroid hormone, which plays an important role in calcium homeostasis. This condition has been diagnosed more frequently recently and can affect multiple organ systems resulting in a variety of signs and symptoms. Hyperparathyroidism can be classified as primary, secondary, or tertiary disease and can result from eutopic or ectopic parathyroid lesions. Parathyroid adenoma is the most common cause of primary hyperparathyroidism, accounting for more than $80 \%$ of cases. Parathyroid hyperplasia is the cause in about $20 \%$ of patients, while parathyroid carcinoma is rare and accounts for less than $1 \%$ of cases. Surgical removal of the abnormal gland(s) is the definite treatment for hyperparathyroidism. Bilateral neck exploration is the classical approach for parathyroidectomy. In recent years, minimally invasive parathyroidectomy is becoming more popular due to the fewer complications and shorter hospital stay. This new approach has placed a greater emphasis on the preoperative localization techniques. Multiple localization techniques have been used, including invasive techniques, anatomical, and scintigraphic imaging modalities. Thallium/pertechnetate subtraction method was introduced in 1980 and was the first method to gain widespread acceptance. It is not widely used now due to the suboptimal characteristics of thallium and the technical difficulties associated with subtraction and registration. The dual-phase method using Tc-99m sestamibi is currently the method of choice for parathyroid localization. It is based on the differential washout rate of sestamibi from the thyroid and abnormal parathyroid glands. The reported sensitivity of this method ranges from $80 \%$ to $90 \%$. The addition of single-photon emission computed tomography (SPECT) and more recently SPECT/CT improves the anatomical localization and helps in the differentiation of the parathyroid from the thyroid lesions. Multiple factors can affect the sensitivity of the scan including the lesion size, cellularity, and the presence of P-glycoprotein. Modification of the imaging protocol may help to avoid false positive or false negative results in certain cases. Positron emission tomography has been recently investigated for possible role in parathyroid imaging and showed promising results with ${ }^{11} \mathrm{C}$-methionine.
\end{abstract}

Keywords: parathyroid, hyperparathyroidism, sestamibi, scintigraphy

\section{Introduction}

The parathyroid gland was the last organ to be recognized in humans and was discovered by Ivar Sandstrom in 1880. In 1915, Friedrich Schlaugenhaufer noticed that bone disease might be caused by an enlarged parathyroid gland. Ten years later, the first successful parathyroidectomy was performed in Vienna by Felix Mandl. ${ }^{1}$

In the past few decades, the frequency of hyperparathyroidism has been increasingly noticed. It affects calcium homeostasis and can result in various complications involving multiple organ systems.
Correspondence: Abdelhamid H Elgazzar Department of Nuclear Medicine, Faculty of Medicine, Kuwait University, P.O. Box 24923, Safat I3 I I 0, Kuwait Email aelgazzar49@hotmail.com (c) (i) (5) 2015 Alenezi et al. This work is published by Dove Medical Press Limited, and licensed under Creative Commons Attribution - Non Commercial (unported, v3.0)

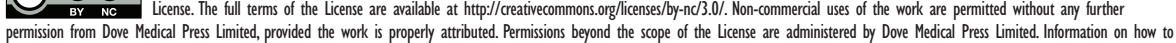
requisstion from Dove Medical Press Limited, provided the work is properly a 
Surgical removal of the abnormal parathyroid gland(s) remains the definite treatment of hyperparathyroidism. ${ }^{2}$ The classical surgical approach is bilateral neck exploration, which has a good success rate in expert hands. Recently, minimally invasive parathyroidectomy is increasingly becoming the technique of choice due to the lower complication rate. This technique placed a greater emphasis on the preoperative localization techniques for abnormal parathyroid glands. ${ }^{3}$

Although normal parathyroid glands are too small to be visualized, parathyroid disease often produces visibly enlarged glands. ${ }^{4,5}$ Multiple imaging techniques using different imaging agents have been used with varying degree of success. Proper interpretation of the imaging studies requires good understanding of the anatomical, embryological, and physiological features of the parathyroid glands.

\section{Basic considerations}

The parathyroid glands have some of the most variable anatomical features among other organs in terms of their shape, size, number, and location. ${ }^{5}$ They are usually ovoid or bean-shaped. Less commonly, the glands may be elongated, flattened into a leaf-like structure, or multilobulated. ${ }^{5,6}$

The size and diameter of the glands vary according to the shape. The normal glands usually measure $4-6 \mathrm{~mm}$ in length, 2-4 mm in width, and $0.5-2 \mathrm{~mm}$ in thickness. ${ }^{6}$ Therefore, the weight of the glands is a better estimate of the glandular tissue and is usually $30-50 \mathrm{mg}$ for each gland, with the largest not exceeding $70 \mathrm{mg} .{ }^{6}$

The weight of the functioning parenchyma is a relatively new parameter and can be calculated from the glandular weight and the relative proportions of the two main glandular components, parenchymal and fat cells. The normal weight of the four glands is usually less than $210 \mathrm{mg}$ and the total parenchymal cell weight is less than $145 \mathrm{mg}{ }^{6}$

Human beings usually have two pairs of glands, but variable numbers may be found occasionally. ${ }^{7}$ About $80 \%-97 \%$ of healthy people have four parathyroid glands, about $5 \%$ have less than four glands, and 3\%-13\% have supernumerary glands. ${ }^{8}$

Understanding the normal and ectopic locations of the parathyroid glands requires good knowledge of their embryological origin. The superior parathyroid glands are derived from the dorsal aspect of the fourth pharyngeal pouch and descend along with the thyroid gland. Because of their shorter migratory pathway, the superior glands are less variable in location. ${ }^{5}$ They are typically located at the cricothyroid junction above the anatomical demarcation of the inferior thyroid artery and the recurrent thyroid nerve..$^{8,9}$
On the other hand, the inferior parathyroid glands are derived from the dorsal aspect of the third pouch and descend along with the thymus. They are more variable in location due to the relatively longer migratory pathway. ${ }^{5}$ They are usually located at the anterolateral or posterolateral aspects of the lower pole of the thyroid. ${ }^{8}$

Ectopic parathyroid glands can be found in variable locations along their migratory pathway. ${ }^{10}$ Ectopic superior glands may be found embedded within the thyroid gland or its capsule because of their shared embryological origin. Ectopic inferior glands may be found along the migratory pathway of the thymus. Their common ectopic locations include the thyrothymic ligament, upper mediastinum, and within the thymus itself. . $^{5,10}$

Histologically, the chief cells represent the majority of the parathyroid parenchymal cells. ${ }^{11}$ These cells contain cytoplasmic fat droplets and are responsible for the secretory function of the gland. Oxyphilic and transitional oxyphilic cells are sparsely present in children and increase to $4 \%-5 \%$ of the parenchymal cells in old age. Ultrastructurally, oxyphilic cells are larger than chief cells and have more eosinophilic cytoplasm because of the abundant mitochondria. ${ }^{11}$ Waterclear cells are inactive and appear vacuolated. ${ }^{4}$

The parathyroid glands secrete parathyroid hormone (PTH) that is responsible for maintaining calcium homeostasis. PTH is a polypeptide that consists of 84 amino acids and is produced mainly from the chief cells. ${ }^{12} \mathrm{PTH}$ controls calcium level through four principal mechanisms: 1) increases calcium absorption from the gastrointestinal tract; 2) stimulates osteoblastic activity; 3) enhances renal tubular reabsorption of calcium; 4) decreases renal tubular reabsorption of phosphate. ${ }^{12}$ The extracellular concentration of calcium controls PTH secretion. PTH is metabolized by Kupffer cells in the liver.

\section{Pathophysiology of hyperparathyroidism}

Hyperparathyroidism is a condition caused by oversecretion of PTH. In recent years, this condition has been diagnosed more frequently due to improvement in the routine laboratory screening and increase in the awareness of this disease. The clinical presentation and complications of hyperparathyroidism depends on the rapidity of its development as well as the degree of hypercalcemia. Muscle weakness, polydipsia, dry skin and itching, memory loss, and anxiety are the five disease-specific symptoms, which usually show significant improvement after successful parathyroidectomy. ${ }^{13}$ Hyperparathyroidism can also result in other abnormalities 
involving multiple organ systems like the genitourinary, gastrointestinal, musculoskeletal, and nervous systems (Table 1). ${ }^{1}$

Hyperparathyroidism is classified as primary, secondary, or tertiary disease. This condition may have familial association as in multiple endocrine neoplasia (MEN) syndrome. ${ }^{14}$ Hyperparathyroidism can occur as a result of eutopic or ectopic disease.

Primary hyperparathyroidism is the most common disease of the parathyroid glands. It is characterized by elevated calcium level due to oversecretion of PTH that results from loss of normal feedback control by extracellular calcium. ${ }^{12}$ In the United States, the incidence of this disease is estimated at 27.7 cases per 100,000 population per year. ${ }^{15}$ Primary hyperparathyroidism is three times more common in females

Table I Clinical manifestation and complications of hyperparathyroidism

\begin{tabular}{ll}
\hline Organs & Clinical manifestation \\
\hline General & Weakness \\
& Easy fatigability \\
& Weight loss \\
& Pruritus \\
& Hypertension \\
& Metastatic calcification \\
& Keratitis, conjunctivitis \\
& Renal stones \\
& Nephrocalcinosis \\
& Renal failure \\
Renal & Polyuria \\
& Nocturia \\
& Metabolic acidosis \\
& Nausea \\
Gomiting \\
Constipation \\
Increased thirst \\
Loss of appetite \\
Abdominal pain \\
Peptic ulcers \\
Heartburn \\
Pancreatitis \\
Sleeplessness \\
Poor concentration \\
Depression \\
Impaired thinking \\
Sensory and motor neuropathy \\
Psychosis \\
Muscle weakness \\
Pathological fracture \\
Bone and joints pain \\
Osteopenia \\
Chondrocalcinosis \\
Brown tumor \\
Osteitis fibrosa cystica \\
\end{tabular}

Note: Adapted from Elgazzar and Alenezi. ${ }^{64}$ than males. ${ }^{12}$ More than $80 \%$ of the patients with primary hyperparathyroidism have a solitary parathyroid adenoma. Parathyroid hyperplasia is the cause in less than $20 \%$ of patients. Parathyroid carcinoma may be the cause in less than $1 \%$ of patients. Ectopic secretion of PTH or biologically similar peptides is a rare cause and is associated with bronchogenic or renal cell carcinoma. ${ }^{4}$

Secondary hyperparathyroidism is simply a compensatory mechanism in response to chronic hypocalcemia, which is frequently caused by chronic renal failure. In this condition, the renal production of the active form of vitamin D is reduced, resulting in decreased intestinal absorption of calcium. Also, there is decreased renal tubular excretion of phosphate resulting in hyperphosphatemia. ${ }^{12}$ In an attempt to compensate for hypocalcemia and hyperphosphatemia, generalized parathyroid hyperplasia occurs and results in overproduction of PTH. ${ }^{16}$ Other less common causes of secondary hyperparathyroidism include malabsorption syndrome, dietary rickets, and ingestion of drugs like phenytoin, phenobarbital, and laxatives. ${ }^{4}$

Tertiary hyperparathyroidism is a complication of longstanding secondary hyperparathyroidism. The parathyroid glands develop autonomous hyperplasia, which may not regress even after correction of the underlying condition. ${ }^{4}$

Eutopic parathyroid disease results from abnormal parathyroid glands located within their typical anatomical location $^{8,9}$ and represents about $80 \%-90 \%$ of all cases. ${ }^{17}$ The parathyroid glands, interestingly, demonstrate constant symmetry, which is helpful in the surgical exploration of eutopic disease. ${ }^{8}$

Ectopic parathyroid disease is less common than eutopic disease and results from abnormal parathyroid glands outside their typical anatomical location. Ectopic superior parathyroid adenoma may be found at the superior-posterior mediastinum and can be retropharyngeal, retroesophageal, or at the trachea-esophageal groove. Rarely, superior parathyroid adenoma can be intrathyroidal. Both the right and left superior glands have similar frequency of ectopia. ${ }^{17}$ Ectopic inferior glands, on the other hand, are more common and represent $10 \%-13 \%$ of all cases of hyperparathyroidism. ${ }^{17}$ Ectopic tissue can be found along the embryological migratory pathway of the inferior glands from the angle of the mandible to the mediastinum. The common sites include the upper mediastinum, thymus, aortopulmonary window, carotid sheath, vagus nerve, thyrothymic ligament, and pericardium. ${ }^{10,17-20}$

Parathyroid adenoma is the most common cause of hyperparathyroidism. ${ }^{21}$ It is a benign tumor that is usually 
solitary, although double or multiple adenomas can occur in up to $12 \%$ of patients with primary hyperparathyroidism. ${ }^{22}$ These adenomas usually weigh $300 \mathrm{mg}$ to $1 \mathrm{~g}$. The degree of hypercalcemia was found to correlate with the tumor size. ${ }^{23}$ Microscopically, parathyroid adenoma is formed predominantly of chief cells, although a mixture of oxyphil cells and transitional oxyphil cells can be also found. ${ }^{21}$ Multiple other variants of parathyroid adenomas had been recognized including cystic adenoma, lipoadenoma, and oncocytic adenoma. ${ }^{4}$

Parathyroid hyperplasia is a less common cause of hyperparathyroidism and accounts for less than $20 \%$ of all cases. It usually affects the glands to varying degrees. Commonly, one or two glands may be normal in size, although microscopic signs of endocrine hyperfunction are present in all the glands. Chief-cell hyperplasia is the most common form. Hyperplasia affects the glands asymmetrically in primary hyperparathyroidism. In secondary hyperparathyroidism, the hyperplastic glands are more uniformly enlarged. In tertiary hyperparathyroidism, the glands are markedly and asymmetrically enlarged. ${ }^{4}$

Parathyroid carcinoma is a rare cause of hyperparathyroidism. ${ }^{24}$ The tumor has no sex preference and is usually found in patients from 30 to 60 year of age. Parathyroid carcinoma is usually larger than adenoma and is usually lobulated, firm, and attached to surrounding soft tissue structures. ${ }^{25}$ Patients with parathyroid carcinoma usually have significantly high PTH and calcium levels and present with severe and atypical clinical picture. The bone and kidney are often more severely and frequently affected. ${ }^{21}$

\section{Treatment of hyperparathyroidism}

Surgery is the only curative treatment for primary hyperparathyroidism. Parathyroidectomy with bilateral neck exploration and intraoperative localization by the surgeon is the classical surgical technique..$^{3,5,26}$ This technique has a good success rate in more than $90 \%$ of cases in experienced hands. ${ }^{12}$ However, intraoperative visual identification of the glands is not always easy and can be challenging, particularly with removal of multiple glands and with reoperation. This may result in prolonged surgical exploration, which is associated with higher incidence of complications such as injury of the recurrent laryngeal nerve. ${ }^{27}$ Preoperative parathyroid localization was only reserved typically for difficult cases. ${ }^{12}$

In recent years, minimally invasive parathyroidectomy is becoming the procedure of choice for single parathyroid adenoma which represents about $80 \%$ of hyperparathyroidism cases. ${ }^{28}$
This approach has many advantages over the classical one. It has less morbidity, shorter hospital stay time, and better cosmetic results. ${ }^{5,29}$ The success of the minimally invasive technique depends on accurate preoperative localization of the abnormal gland(s). Therefore, greater emphasis has been placed on the preoperative localization studies. ${ }^{12}$

\section{Preoperative localization}

Several techniques have been used to guide the surgeons to localize the abnormal parathyroid gland(s). Invasive localization techniques, like parathyroid arteriography and selective venous sampling, are reliable. However, they are technically difficult, time consuming, and involve some risks like catheter injury, hematoma, contrast-induced nephropathy, anaphylaxis, and stroke. ${ }^{5}$ Therefore, they are not routinely performed and reserved for difficult cases with recurrent or persistent hyperparathyroidism. ${ }^{5}$

Many noninvasive localization studies, morphologic and scintigraphic, have been used clinically but none of them are considered ideal. Multiple morphologic modalities, like ultrasound, computed tomography (CT), and magnetic resonance, have been used for parathyroid localization providing excellent image resolution and contrast. These modalities, on the other hand, have inadequate and variable accuracy and they can't differentiate functional parathyroid tissue from other types of tissues. Ultrasound is operator dependent and, therefore, has a wide range of accuracy ranging from $36 \%$ to $76 \%$. CT and magnetic resonance have similar range of sensitivity ranging from $46 \%$ to $76 \%$ and from $50 \%$ to $78 \%$ respectively. ${ }^{30-34}$

\section{Scintigraphic imaging}

Multiple scintigraphic studies can be used to localize abnormal parathyroid glands in patients with biochemically proven hyperparathyroidism. A radiotracer that is specific for the parathyroid gland should ideally be used for this purpose. Unfortunately, such a radiotracer does not exist currently. Therefore, different methods with multiple radiotracers had been used with different success rates.

The dual isotope method was the first method to gain widespread acceptance for parathyroid imaging. It was first introduced in the early 1980 s. $^{35}$ Thallium-201 is the main radiotracer used in this method. It is a cationic analog of potassium and was first used for myocardial perfusion imaging. Thallium-201 accumulates in both the thyroid and the parathyroid glands. Therefore, the thyroid activity should be subtracted from the image to allow for the identification of the parathyroid activity. This can be achieved by the use of 
another radiotracer like iodine-123 or Tc-99m pertechnetate which only accumulate in the thyroid gland. The thyroid activity is then digitally subtracted from thallium image resulting in a subtraction image that represents activity only within the abnormal parathyroid gland. This method has many limitations due to the suboptimal physical characteristics of thallium-201. Its photon energy is $69-80 \mathrm{KeV}$, which is not ideal for the current gamma cameras, resulting in poor image quality. It also delivers a high radiation dose to the patient, warranting limitation the administered dose. In addition, digital subtraction of the images may be difficult due to technical problems such as patient motion between two scans. ${ }^{12}$

The single radiopharmaceutical dual-phase method is currently the most widely used method for preoperative localization. Taillefer et $\mathrm{al}^{36}$ introduced this single isotope, dual-phase method, which is based on the differential washout rates of sestamibi from the thyroid and abnormal parathyroid glands. It was observed that sestamibi is washed out less rapidly from the parathyroid tissue than from thyroid, where it is retained for a longer time, presumably due to the presence of more mitochondria-rich oxyphil cells. This method is easy to perform as it requires a single injection of Tc-99m sestamibi. Early images are then acquired at 10-20 minutes followed by delayed images at 2-3 hours after the radiotracer injection (Figure 1). An additional image of the chest is also routinely obtained as ectopic parathyroid adenoma can be found in the upper mediastinum.

In addition to the dual isotope and dual-phase methods, various other techniques have been used in special cases. Some institutions combine the subtraction method with the dual-phase method by obtaining an additional image of the thyroid, either with Iodine-123 or Tc-99m pertechnetate (Figure 2). This technique is useful in patients with thyroid abnormalities to avoid false positive results from retention of sestamibi in thyroid lesions. ${ }^{12}$ Other institutions obtain a dynamic pinhole acquisition over the neck, at a rate of
2 minutes/frame, following the administration of sestamibi. This is followed by the administration of Tc-99m pertechnetate to acquire a thyroid image.$^{37}$ This protocol is especially helpful in cases of parathyroid lesions with rapid washout of sestamibi.

Single-photon emission computed tomography (SPECT) has been used routinely in some institutions. SPECT is useful in the localization of ectopic lesions and in the differentiation of parathyroid from thyroid lesions. ${ }^{12}$ SPECT can also be combined with CT (SPECT/CT) to improve the anatomical localization of the lesion in relation to other structures (Figure 3A and B). This technique is helpful in preoperative localization and performing scan-directed minimally invasive surgery. ${ }^{2}$

Positron emission tomography (PET) has been recently used for parathyroid imaging using multiple radiotracers. Fluorine-18-fluorodeoxyglucose $\left({ }^{18} \mathrm{~F}-\mathrm{FDG}\right)$ had been used in initial studies, which showed conflicting results in cases of primary hyperparathyroidism. Neumann et $\mathrm{al}^{38}$ compared FDG-PET and sestamibi-SPECT for preoperative localization in 21 patients with primary hyperparathyroidism. They concluded that FDG-PET is more sensitive than sestamibi, with a sensitivity of $86 \%$. On the other hand, Melon et $\mathrm{al}^{39}$ demonstrated a too low sensitivity for preoperative localization of parathyroid adenoma using FDG-PET in seven patients with primary hyperparathyroidism.

${ }^{11} \mathrm{C}$-methionine had also been used with PET imaging and showed more promising results than FDG. Sundin et $\mathrm{al}^{40}$ reported a sensitivity of $85 \%$ for localization with ${ }^{11} \mathrm{C}$ methionine in 32 patients with primary hyperparathyroidism. More recently, Beggs and $\mathrm{Hain}^{41}$ reported a sensitivity of $83 \%$, a specificity of $100 \%$, and an accuracy of $88 \%$ for localizing parathyroid adenoma in 51 patients with hyperparathyroidism, in whom other imaging studies failed to localize the adenoma. Weber et $\mathrm{al}^{42}$ conducted the largest prospective study to date on the use of ${ }^{11} \mathrm{C}$-methionine

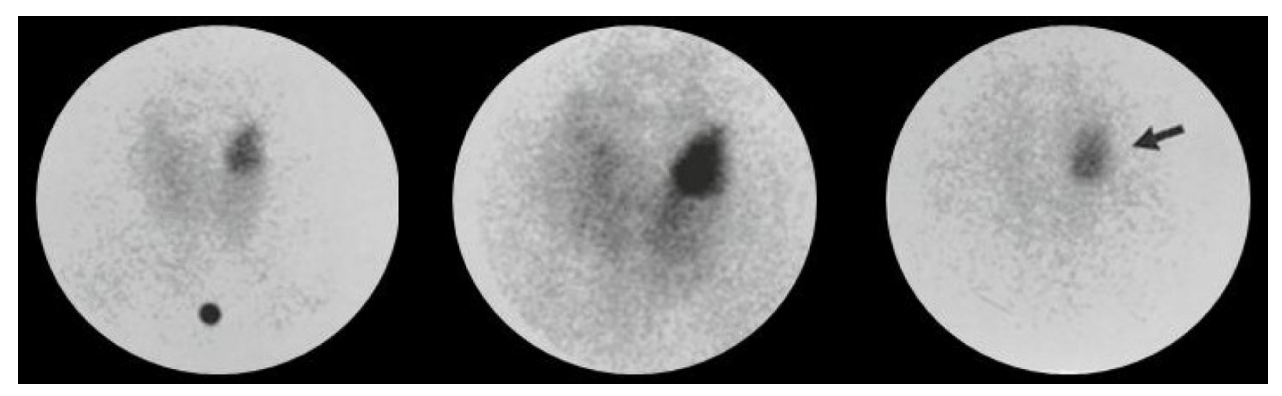

Figure I Results of Tc-99m sestamibi study acquired at I5 and 90 minutes postinjection using pinhole collimator. ${ }^{64}$

Notes: The delayed image shows differential clearance of activity from the thyroid gland, with retained and intense uptake by a large parathyroid adenoma (arrow). Springer, Pathophysiologic Basis of Nuclear Medicine. 3rd ed, Parathyroid gland, 20I4, Elgazzar A, editor. (C) 2014 with permission of Springer Science+Business Media. ${ }^{64}$ 


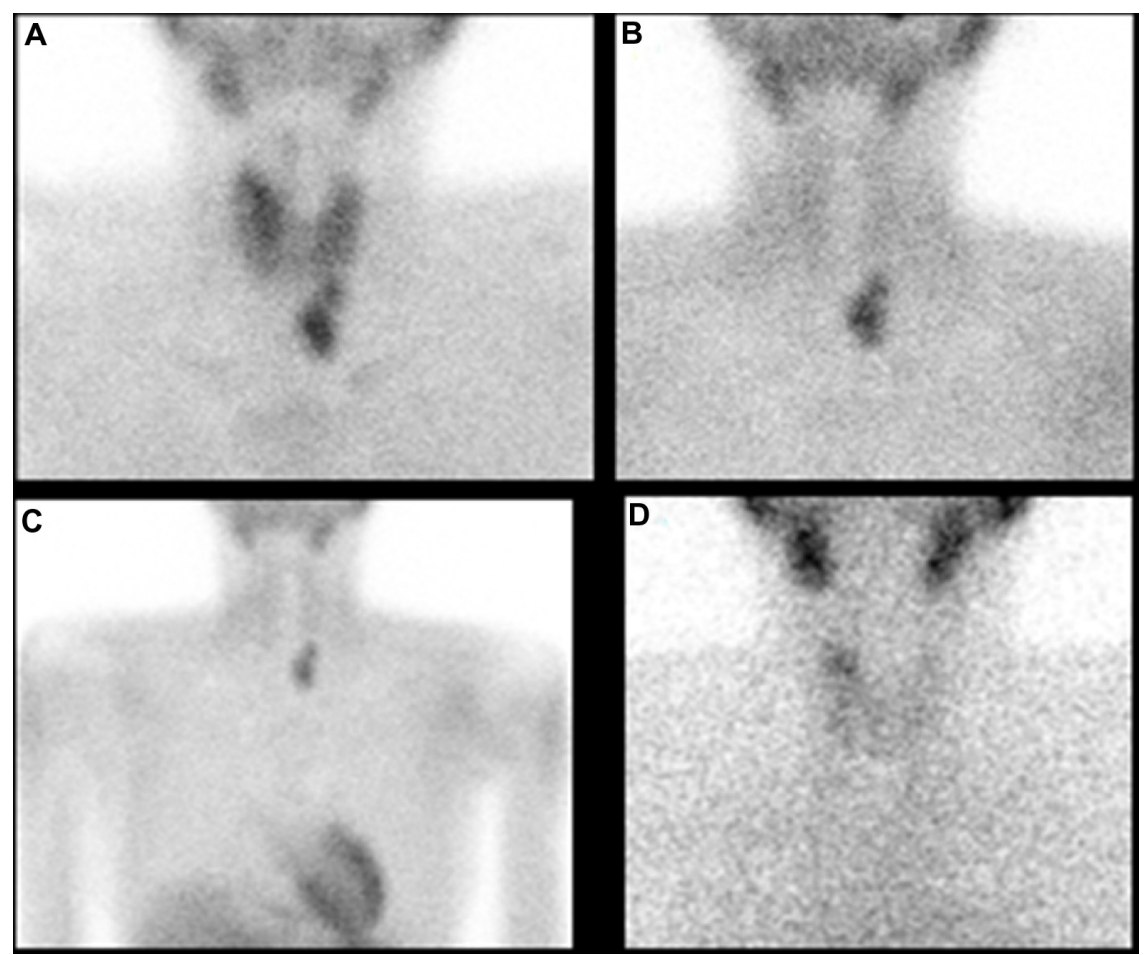

Figure 2 Tc- $99 \mathrm{~m}$ sestamibi study results.

Notes: Tc-99m sestamibi study (A-C) acquired at 15 and 120 minutes postinjection using parallel hole collimator. In addition, Tc-99m pertechnetate study (D) was also obtained using parallel hole collimator. The early image (A) show a focus of increased uptake inferior to the left lower pole that persists on the delayed image (B) after the clearance of the thyroid activity. There is also increased uptake at the right upper pole on the early image (A) which washes out on the delayed image (B). The pertechnetate study (D) shows a corresponding focus of increased uptake at the right upper pole suggesting a thyroid nodule.

A
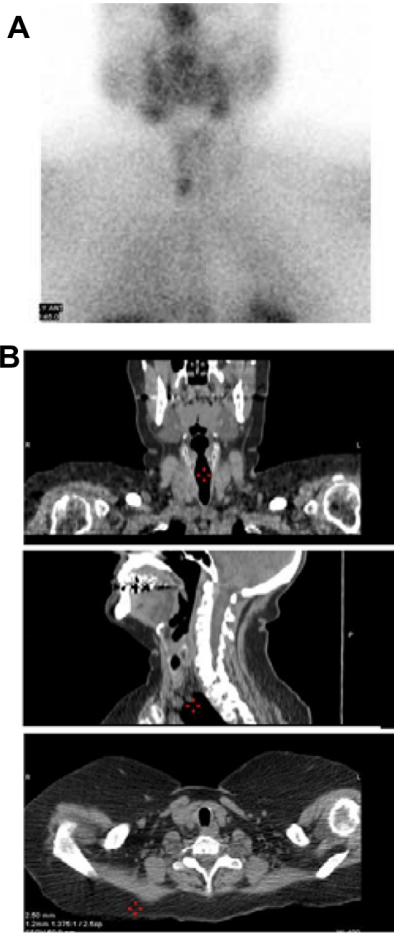

CT
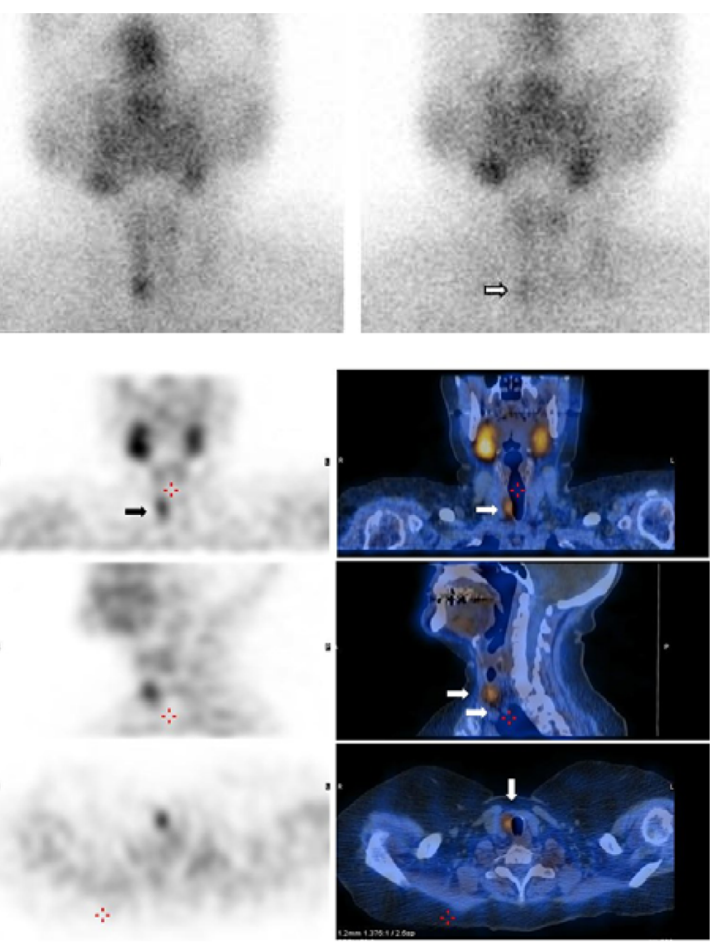

SPECT

FUSED

Figure 3 Tc-99m sestamibi study acquired at 15 and 120 minutes postinjection using parallel hole collimator.

Notes: Planar images $(\mathbf{A})$ reveal a focus of increased uptake at the right lower pole seen on the early image and persisting on the delayed image (arrow) which showed further clearance of thyroid background activity. SPECT/CT study (B) was also obtained, showing the lesion with better contrast and anatomic localization (arrow).

Abbreviations: CT, computed tomography; SPECT, single-photon emission computed tomography. 
for parathyroid imaging in 102 patients. Despite the high number of concomitant thyroid nodules (34\%) in the study, the reported sensitivity was $91 \%$ and the positive predictive value was $93 \%$. Few case reports suggested a possible role for ${ }^{18} \mathrm{~F}$-choline in localizing ectopic parathyroid adenoma. ${ }^{43}$

\section{Factors affecting scan sensitivity Radiotracer and technique used}

Different techniques had been used for parathyroid imaging using multiple radiotracers such as thallium-201, Tc-99m sestamibi, Tc-99m tetrofosmin, and short-lived PET tracers. Each radiotracer has different characteristics and different uptake mechanisms by the target tissue.

Sestamibi is a lipophilic cationic isonitrile derivative that accumulates in the mitochondria-rich oxyphil cells. ${ }^{44}$ The negative transmembrane potential of the mitochondria is the main factor for sestamibi retention. ${ }^{5}$ It has been reported that P-glycoprotein, a membrane transport protein encoded for by the $M D R$ gene, may also be responsible for sestamibi uptake. This protein also transports other product with similar structure to sestamibi. ${ }^{45}$ Currently, scintigraphy using Tc-99m sestamibi is the preferred method for parathyroid imaging as it is the most sensitive and cost-effective modality for preoperative localization. ${ }^{5,23}$ Due to the variation in the scanning protocols, the reported sensitivity of sestamibi ranges from $80 \%$ to $100 \%{ }^{46,47}$

Tetrofosmin (Myoview ${ }^{\mathrm{TM}}$, GE Healthcare, Princeton, NJ, USA) is a lipophilic cationic diphosphine that has been also used for parathyroid imaging. The use of this radiotracer in dual-phase method is less reliable because it has little washout from the thyroid gland. ${ }^{2}$ Tetrofosmin has been used in a 2-day protocol, using Tc-99m pertechnetate for thyroid imaging and early Tc-99m Tetrofosmin for parathyroid imaging on the next day, and it was successful in detecting adenoma with high accuracy. ${ }^{4}$ Nevertheless, Tetrofosmin has never gained widespread use for parathyroid imaging despite its comparable results with sestamibi. ${ }^{12}$

Thallium-201 is a cationic analog of potassium that is mainly used with the subtraction method for parathyroid imaging. Its mechanism of uptake is dependent on the active transport through the Na/K ATPase pump. ${ }^{12}$ The activity per gram of thyroid and parathyroid tissue is higher for thallium than for sestamibi. Unlike thallium, sestamibi washes out form the thyroid and parathyroid tissues resulting in a higher target to nontarget ratio. ${ }^{44}$ Therefore, sestamibi is superior to thallium in localizing small glands and distinguishing parathyroid lesion from thyroid tissue. ${ }^{48}$ Parathyroid imaging using thallium subtraction protocol is not currently preferred due to technical problems associated with subtraction and misregistration. ${ }^{49,50}$ The reported sensitivity of this method for primary parathyroid adenoma is between $42 \%$ and $96 \%{ }^{2}$

The time of imaging after the radiotracer administration may also affect the scan sensitivity. Multiple timings had been used with no clear consensus on the optimal one. For example, Neumann et $\mathrm{al}^{38}$ imaged at 10 minutes, Bonjer et $\mathrm{al}^{51}$ imaged at 30 minutes, De Feo et $\mathrm{al}^{52}$ imaged at 10 and 90 minutes, Klieger and O'Mara ${ }^{48}$ imaged at 30 and 120 minutes, Mazzeo et $\mathrm{al}^{53}$ imaged at 30 and 180 minutes, and Slater and Gleeson ${ }^{54}$ imaged at 2 hours.

The type of collimator used is another important factor that can affect the scan sensitivity. The parathyroid lesions are usually too small and difficult to be visualized. The pinhole collimator magnifies these small lesions and provides the highest resolution among other collimators (Figure 1). Therefore, the sensitivity improves with the use of pinhole collimator. ${ }^{12}$ Parallel hole collimator has also been used in parathyroid imaging. It allows inclusion of both the neck and chest in the field of view (Figure 2A-D). This is important in cases of ectopic lesions which can be found in the mediastinal area. Many institutions use the pinhole collimator to obtain images of the neck, with the addition of chest image as a routine protocol.

The added sensitivity with using SPECT is controversial. Multiple studies using SPECT showed different sensitivities ranging from $53 \%$ to $87 \% .^{38,51,52,54,55}$ In a recent meta-analysis performed by Cheung et al, ${ }^{56}$ the pooled sensitivity of sestamibi using SPECT was 78.9\% (range 64\%-90.6\%).

\section{Lesion characteristics}

Multiple lesion-specific features were found to affect the scan sensitivity. These included the lesion size, cellularity, and the presence of $\mathrm{P}$-glycoprotein. In a recent study done by Takebayashi et al, ${ }^{57}$ it was observed that sestamibi uptake was correlated with the size and cellularity of the abnormal parathyroid lesions. Another study conducted by Carpentier et $\mathrm{al}^{58}$ found a positive correlation between sestamibi uptake and the presence of oxyphil cells in parathyroid adenoma. Thallium scintigraphy was also shown to detect parathyroid lesions with higher number of mitochondria-rich oxyphil cells. ${ }^{59}$ In a recent retrospective study involving 63 patients, Bleier et $\mathrm{al}^{26}$ found a statistically significant correlation between sestamibi uptake and oxyphil-cell-dominant adenomas.

P-glycoprotein or $M D R$ gene expression was found to limit the sensitivity of the sestamibi scan. ${ }^{60}$ This may be attributed to the increased efflux of the radiotracer from the 
cells that express this protein. ${ }^{61}$ Sestamibi scan was also found to have lower sensitivity in detecting multigland disease compared to single adenoma. In a study involving 651 patients, Nichols et $\mathrm{al}^{37}$ found that sestamibi scan sensitivity decreases as the number of parathyroid lesions increase. ${ }^{37}$

\section{Sestamibi kinetics and imaging}

Dual-phase protocol using sestamibi is the preferred parathyroid imaging technique. It depends on the differential washout rates of sestamibi from the thyroid and parathyroid glands. The scan sensitivity is limited in cases with atypical washout, like rapid parathyroid washout or delayed thyroid washout.

Rapid parathyroid washout is associated with parathyroid hyperplasia and P-glycoprotein expression. ${ }^{2,60-62}$ In these cases, it is reasonable to modify the scanning protocol to obtain additional interval images between the standard early and delayed images. Another useful protocol is to acquire dynamic images over the neck, followed by static images every 20 minutes.

Delayed thyroid washout occurs in cases of thyroid disease such as thyroid adenoma, thyroid carcinoma, multinodular goiter, and Hashimoto thyroiditis. ${ }^{63}$ Acquiring extended delayed images may be helpful in these cases. The addition of SPECT or SPECT/CT is also helpful in differentiating the anteriorly located thyroid lesions from the posteriorly located parathyroid lesions. ${ }^{12}$ Another useful protocol is to acquire a thyroid image using either iodine-123 or Tc-99m pertechnetate and subsequently subtract it from the sestamibi image to remove the thyroid activity (Figure 2).

\section{Pitfalls}

Multiple other causes can result in false positive (FP) and false negative (FN) results (Table 2 ). The most common cause of false positive result is thyroid nodules. Other

Table 2 Causes of false positive and false negative results of Tc-99m sestamibi scan

\begin{tabular}{ll}
\hline False positive causes & False negative causes \\
\hline Thyroid abnormalities & Small size \\
Thyroid nodules & Parathyroid hyperplasia \\
Multinodular goiter & Multigland disease \\
Thyroiditis & P-glycoprotein (MDR) \\
Thyroid cancer & Few oxyphil cells \\
Supraclavicular lymphadenopathy & Ectopic adenoma \\
Lymphoma & \\
Sarcoidosis (thoracic) & \\
Brown tumors & \\
Brown fat & \\
\hline
\end{tabular}

benign and malignant thyroid conditions, like multinodular goiter, inflammatory thyroiditis, and thyroid carcinoma, may also result in FP results. Cervical lymphadenopathy, lymphoma, and sarcoidosis are other possible causes of FP results. ${ }^{5,12}$ On the other hand, FN results are commonly seen with small adenoma, parathyroid hyperplasia, multigland disease, the presence of P-glycoprotein, and in lesions with few oxyphil cells. ${ }^{12,61}$

\section{Summary}

The recent trend to shift from the classical bilateral neck exploration to the minimally invasive parathyroidectomy had placed a greater emphasis on the preoperative localization techniques. Currently, Tc-99m sestamibi dual-phase imaging is the preferred imaging technique. Atypical washout of the tracer from the thyroid and parathyroid tissues may result in FP or FN results. Modification of the standard protocol may be helpful in these cases. The addition of SPECT or SPECT/ CT improves the anatomical localization and helps in the differentiation of parathyroid from the thyroid lesions.

\section{Disclosure}

The authors report no conflicts of interest in this work.

\section{References}

1. Carney JA. The glandulaeparathyroideae of Ivar Sandstrom. Contributions from two continents. Am J Surg Pathol. 1996;20:1123-1144.

2. Kettle AG, O'Doherty M. Parathyroid imaging: how good is it and how should it be done? Semin Nucl Med. 2006;36:206-211.

3. Uldelsman R. Six hundred fifty-six consecutive explorations for primary hyperparathyroidism. Ann Surg. 2002;235(5):665-672.

4. Elgazzar AH. Parathyroid gland. In: The Pathophysiologic Basis of Nuclear Medicine. 2nd ed. New York, NY: Springer; 2006:222-237.

5. Kunstman JW, Kirsch JD, Mahajan A, Udelsman R. Clinical review: parathyroid localization and implications for clinical management. J Clin Endocrinol Metab. 2013;98:902-912.

6. Akerstrom G, Grimelius L, Johansson H, Lundquist H, Pertoft H, Bergstrom R. The parenchymal cell mass in normal human parathyroid glands. Acta Pathol Microbiol Immunol Scand. 1981;89(A):367.

7. Maxon HR, Elgazzar AH. Parathyroid imaging. In: Gelfand G, Thomas S, editors. Effective Use of Computers in Nuclear Medicine. New York, NY: McGraw Hill; 1988:485-496.

8. Akerstrom G, Malmaeus J, Bergstrom R. Surgical anatomy of human parathyroid glands. Surgery. 1984;95:15-21.

9. Wang CA. The anatomic basis of parathyroid surgery. Ann Surg. 1976;183:271-275.

10. Zerizer I, Parsai A, Win Z, Al-Nahhas A. Anatomical and functional localization of ectopic parathyroid adenomas: 6-year institutional experience. Nucl Med Commun. 2011;32:496-502.

11. Ritter CS, Haughey BH, Miller B, Brown A. Differential gene expression by oxyphil and chief cells of human parathyroid glands. J Clin Endocrinol Metab. 2012;97:E1499-E1505.

12. Palestro C, Tomas M, Tronco G. Radionuclide imaging of the parathyroid glands. Semin Nucl Med. 2005;35:266-276.

13. Walker RP, Paloyan E, Gopalsami C. Symptoms in patients with primary hyperparathyroidism: muscle weakness or sleepiness. Endocr Pract. 2004;10:404-408. 
14. Skogseid B, Rastad J, Oberg K. Multiple endocrine neoplasia type 1. Endocrinol Metab Clin North Am. 1994;23:1-17.

15. Heath H III. Clinical spectrum of primary hyperparathyroidism: evolution with changes in medical practice and technology. $J$ Bone Miner Res. 1991;6:S63-S70.

16. Sy WM, Mittal AK. Bone scan in chronic dialysis patients with evidence of secondary hyperparathyroidism and renal osteodystrophy. $\mathrm{Br} J$ Radiol. 1975;48:878-884.

17. Thompson NW, Eckhauser FE, Harness JK. The anatomy of primary hyperparathyroidism. Surgery. 1982;92:814-821.

18. Simeone DM, Sandelin K, Thompson NW. Undescended superior parathyroid gland: a potential cause of failed cervical exploration for hyperparathyroidism. Surgery. 1995;118:949-956.

19. Shen W, Duren M, Morita E, et al. Reoperation for persistent or recurrent primary hyperparathyroidism. Arch Surg. 1996;131:861-869.

20. Doppman JL, Skarulis MC, Chen CC, et al. Parathyroid adenomas in the aortopulmonary window. Radiology. 1996;201:456-462.

21. Fleischer J, Becker C, Hamele-Bena D, et al. Oxyphil parathyroid adenoma: a malignant presentation of a benign disease. J Clin Endocrinol Metab. 2004;89:5948-5951.

22. Tezelman S, Shen W, Shaver JK, et al. Double parathyroid adenomas: clinical and biochemical characteristics before and after parathyroidectomy. Ann Surg. 1993;218:300-309.

23. Akerstrom G, Rastad J, Ljunghall S, Johnsson H. Clinical and experimental advances in sporadic primary hyperparathyroidism. Acta Chir Scand. 1990;156:23-28.

24. Cook M, Qureshi Y, Todd C, Cummins R. An unusual ectopic location of a parathyroid carcinoma arising within the thyroid gland. $J$ Clin Endocrinol Metab. 2012;97:1829-1833.

25. Lack CA, Rarber JL, Rubin E. The endocrine system. In: Rubin E, Farber JL, editors. Pathology. 3rd ed. Philadelphia, PA: LippincottRaven; 1999:1179-1183.

26. Bleier B, LiVolsi V, Chalian A, et al. Technetium Tc 99m sestamibi sensitivity in oxyohil cell-dominant parathyroid adenomas. Arch Otolaryngol Head Neck Surg. 2006;132:779-782.

27. Wang CA. Parathyroid re-exploration: a clinical and pathological study of 112 cases. Ann Surg. 1977;186:140.

28. Assalia A, Inabnet WB. Endoscopic parathyroidectomy. Otolaryngol Clin North Am. 2004;37:871-886.

29. Thomas SK, Wishart GC. Trends in surgical techniques. Nucl Med Commun. 2003;24:115-119.

30. Erdman WA, Breslau NA, Weinreb JC, et al. Noninvasive localization of parathyroid adenomas: a comparison of X-ray computerized tomography, ultrasound, scintigraphy and MRI. Magn Reson Imaging. 1989;7:187-194.

31. Auffermann W, Gooding GA, Okerlund MD, et al. Diagnosis of recurrent hyperparathyroidism: comparison of MR imaging and other imaging techniques. AJR Am J Roentgenol. 1988;150:1027-1033.

32. Peck WW, Higgins CR, Fisher MR, Ling M, Okerland MD, Clark OH. Hyperparathyroidism: comparison of MR imaging with radionuclide scanning. Radiology. 1987;163:415-420.

33. Levin KE, Gooding GA, Okerlund M, et al. Localizing studies in patients with persistent or recurrent hyperparathyroidism. Surgery. 1987;102:917-925.

34. Miller DL, Doppman JR, Shawker TH, et al. Localization of parathyroid adenomas in patients who have undergone surgery. Part I. Noninvasive imaging methods. Radiology. 1987;162:133-137.

35. Ferlin G, Borsato N, Camerani M, Conte N, Zotti D. New perspective in localizing enlarged parathyroids by technetium-thallium subtraction scan. J Nucl Med. 1983;24:438-441.

36. Taillefer R, Boucher Y, Potvin C, Lambert R. Detection and localization of parathyroid adenomas in patients with hyperparathyroidism using a single radionuclide imaging procedure with Tc-99m sestamibi (double phase study). J Nucl Med. 1992;33:1801-1807.

37. Nichols K, Tomas M, Tronoco G, Palestro C. Sestamibi parathyroid scintigraphy in multigland disease. Nucl Med Commun. 2012;33(1): $43-50$.
38. Neumann DR, Esselstyn CB, MacIntyre WJ, et al. Comparison of FDG-PET and sestamibi SPECT in primary hyperparathyroidism. J Nucl Med. 1996;37:1809-1815.

39. Melon P, Luxen A, Hamoir E, Meurisse M. Fluorine-18-fluorodeoxyglucose positron emission tomography for preoperative parathyroid imaging in primary hyperparathyroidism. Eur J Nucl Med. 1995;22:556-558.

40. Sundin A, Johansson C, Hellman P, et al. PET and parathyroid L-[carbon-11]methionine accumulation in hyperparathyroidism. $J \mathrm{Nucl}$ Med. 1996;37:1766-1770.

41. Beggs AD, Hain SF. Localization of parathyroid adenomas using ${ }^{11} \mathrm{C}$-methionine positron emission tomography. Nucl Med Commun. 2005;26:133-136.

42. Weber T, Maier-Funk C, Ohlhauser D, et al. Accurate preoperative localization of parathyroid adenomas with C-11 methionine PET/CT. Ann Surg. 2013;257:1124-1128.

43. Quak E, Lheureux S, Renzik Y, Bardet S, Aide N. F18-choline, a novel tracer for parathyroid adenoma? J Clin Endocrinol Metab. 2013;98(8):3111-3112.

44. O'Doherty MJ, Kettle AG, Wells P, Collins RE, Coakley AJ. Parathyroid imaging with technetium-99m-sestamibi: preoperative localization and tissue uptake studies. J Nucl Med. 1992;33(3):313-318.

45. Piwnica-Worms D, Chiu ML, Budding M, Kronauge JF, Kramer RA, Croop JM. Functional imaging of multidrug resistant P-glycoprotein with an organotechnetium complex. Cancer Res. 1993;53:977-984.

46. Mitchell BK, Merrell RC, Kinder BK. Localization studies in patients with hyperparathyroidism. Endocr Surg. 1995;75:483-498.

47. Akerstrom G, Rudberg C, Grimelius L, et al. Histologic parathyroid abnormalities in an autopsy series. Hum Pathol. 1986;17:520-527.

48. Klieger P, O'Mara R. The diagnostic utility of dual phase Tc- $99 \mathrm{~m}$ sestamibi parathyroid imaging. Clin Nucl Med. 1998;23:208-211.

49. Goris ML, Basso LV, Keeling C. Parathyroid imaging. J Nucl Med. 1991;32:887-889.

50. Elgazzar AH, Maxon HR, Hertzberg V, et al. Parathyroid scintigraphy with and without thyroid hormone suppression. Proceedings of the Eastern Great Lakes Chapter, Society of Nuclear Medicine, Niagara Falls, NY, 1985.

51. Bonjer HJ, Bruining HA, Valkema R, et al. Single radionuclide scintigraphy with $99 \mathrm{~m}$-technetium-sestamibi and ultrasonography in hyperparathyroidism. Eur J Surg. 1997;163:27-32.

52. De Feo ML, Colagrande S, Biagini C, et al. Parathyroid glands: combination of $99 \mathrm{mTc}$ MIBI scintigraphy and US for demonstration of parathyroid glands and nodules. Radiology. 2000;214:393-402.

53. Mazzeo S, Caramella D, Lencioni R, et al. Comparison among sonography, double-tracer subtraction scintigraphy, and doublephase scintigraphy in the detection of parathyroid lesions. AJR Am J Roentgenol. 1996;166:1465-1470.

54. Slater A, Gleeson FV. Increased sensitivity and confidence of SPECT over planar imaging in dual-phase sestamibi for parathyroid adenoma detection. Clin Nucl Med. 2005;30:1-3.

55. Civelek AC, Ozalp E, Donovan P, Udelsman R. Prospective evaluation of delayed technetium-99m sestamibi SPECT scintigraphy for preoperative localization of primary hyperthyroidism. Surgery. 2002;131:149-157.

56. Cheung K, Wang TS, Farrokhyar F, Roman SA, Sosa JA. A metaanalysis of preoperative localization techniques for patients with primary hyperparathyroidism. Ann Surg Oncol. 2012;19:577-583.

57. Takebayashi S, Hidai H, Chiba T, Takaga Y, Nagatani Y, Matsubara S. Hyperfunctional parathyroid glands with Tc-99m MIBI scan: semiquantitaive analysis correlated with histologic findings. $J$ Nucl Med. 1999;40:1792-1797.

58. Carpentier A, Jeannotte S, Verrault J, et al. Preoperative localization of parathyroid lesions in hyperparathyroidism: relationship between technetium-99m-MIBI and oxyphil cell count. J Nucl Med. 1998;39: 1441-1444.

59. Sandrock D, Merino MJ, Norton JA, Neumann RD. Ultrastructural histology correlates with results of Thallium-201/Tc-99m parathyroid subtraction scintigraphy. J Nucl Med. 1993;34:24-29. 
60. Kao A, Shiau YC, Tsai SC, Wang JJ, Ho ST. Technetium-99m methoxyisobutylisonitrile imaging for parathyroid adenoma: relationship to P-glycoprotein or multidrug resistance-related protein expression. Eur J Nucl Med Mol Imaging. 2002;29:1012-1015.

61. Mehta N, Ruda J, Kapadia S, Boyer P, Hollenbeak C, Stack B. Relationship of technetium Tc $99 \mathrm{~m}$ sestamibi scans to histopathological features of hyperfunctioning parathyroid tissue. Arch Otolaryngol Head Neck Surg. 2005;131:493-498.

62. Lee VS, Wilkinson RH, Leight GS, Coogan AC, Coleman RE. Hyperparathyroidism in high-risk surgical patients: evaluation with double-phase technetium-99m sestamibi imaging. Radiology. 1995;197: $627-633$.
63. McHenry CR, Lee K, Saadey J, et al. Parathyroid localization with technetium-99m-sestamibi: a prospective evaluation. J Am Coll Surg. 1996;183:25-30.

64. Elgazzar A, Alenezi S. Parathyroid gland. In: Elgazzar A, editor. Pathophysiologic Basis of Nuclear Medicine. 3rd ed. Berlin, Germany: Springer; 2014.

\section{Publish your work in this journal}

Research and Reports in Nuclear Medicine is an international, peerreviewed, open access journal publishing original research, reports, reviews and commentaries on all areas of nuclear medicine. The manuscript management system is completely online and includes a very quick and fair peer-review system. Visit http://www.dovepress.com/ testimonials.php to read real quotes from published authors. 